\title{
Challenges and Opportunities for the Textile Industry in Ghana: A Study of the Adinkra Textile Sub-Sector
}

\author{
Josephine Aboagyewaa-Ntiri ${ }^{1,2}$ \& Kwabena Mintah ${ }^{3}$ \\ ${ }^{1}$ School of Fashion and Textiles, RMIT University, Melbourne, Australia \\ ${ }^{2}$ Faculty of Technology Education, University of Education, Winneba, Ghana \\ ${ }^{3}$ School of Property, Construction and Project Management, RMIT University, Melbourne, Australia \\ Correspondence: Josephine Aboagyewaa-Ntiri, School of Fashion and Textiles, RMIT University, Melbourne, \\ Australia. E-mail: Josephine.Aboagyewaa-Ntiri@rmit.edu.au
}

Received: November 21, 2015

Accepted: December 16, 2015 Online Published: January 25, 2016

doi: 10.5539/ibr.v9n2p127

URL: http://dx.doi.org/10.5539/ibr.v9n2p127

\begin{abstract}
The purpose of the study is to examine the challenges facing the Ghanaian textile industry with emphasis on the Adinkra textile cloth printing sub sector in Ghana, as well as opportunities for improving the industry. The sub sector is distinct and has different dynamics from other sub sectors of the broader textile industry. The study informs policy makers and private sector on the factors resulting in the decline of the Adinkra textile sub sector and the need to sustain the sub sector of the textiles industry due to its heritage importance and contribution to the economy. It also examines potential business opportunities for local and international firms to invest in the textile sub market for expansion and profitability. An empirical research design with mixed-methods approach was used in this study. A qualitative approach (semi-structured interviews) was used to collect the data, coded and analysed using standard NVivo software which generated quantitative outcomes for descriptive statistical analysis. Qualitative approach was also used to interpret the findings of the study. The results indicated that, factors such as lack of access to capital, outmoded forms of technology, issues with supply chain and nature of the dyes for printing the textile cloths are primarily responsible for the declining state of the sub sector. The implications of the challenges and the declining state of the sub sector are discussed and solutions proffered to solve the challenges.
\end{abstract}

Keywords: Adinkra cloth, challenges, business opportunities, textiles

\section{Introduction}

In the $21^{\text {st }}$ century, there is no doubt that, small and medium enterprises (SMEs) play a significant role in the economic development of a country. Through trade liberalisation of the 1980's, the textile manufacturing sector of which the Adinkra small scale textiles cloth printing is a sub-sector, has been plagued with a number of challenges. This is compounded by the onset of the information and digital age on the industry which has shaped the industry products and processes. This has affected the Adinkra textile cloth production sub-sector tremendously; hence the Adinkra textile cloth production is now in a declining state.

Historically, the total number of large and medium sized textile manufacturing companies in Ghana by mid-1970's was in excess of 16 companies (Quartey, 2006) whereas the garment industry also had about 138 medium and large-scale garment manufacturing companies (Quartey \& Abor, 2011). In sharp contrast, several factors ranging from unfavourable and inconsistent policies emanating from the central Government to market forces have resulted in a consistent decline (refer to Table 1 for the statistics). Statistically, the decline had been drastic that by March 2005, a count of the major companies existing in the industry was Ghana Textile Manufacturing Company (GTMC), Akosombo Textile Limited (ATL), Ghana Textile Product (GTP), and Printex (Quartey \& Abor, 2011). Table 1 shows a drastic decline of total number of employers and yards of fabric produced between 1977 and 2005. For example, 25000 people were employed in 1977 and dropped to 2961 workers in 2005. 
Table 1. Decline of the textile industry in Ghana

\begin{tabular}{lccc}
\hline Year & Total number of employers & Percentage ( \%) change in employment & Yards of fabric produced \\
\hline $\mathbf{1 9 7 7}$ & 25,000 & - & 129 million \\
$\mathbf{1 9 9 5}$ & 7,000 & $72 \%$ & 46 million \\
$\mathbf{2 0 0 0}$ & 5,000 & $28 \%$ & 65 million \\
$\mathbf{2 0 0 5}$ & 2,961 & $41 \%$ & 39 million \\
\hline
\end{tabular}

Source: Adapted from Quartey and Abor (2011).

Quartey and Abor (2011) argued that, local consumers in the Ghanaian market prefer the locally manufactured fabrics as compared to the imported fabrics from both the neighbouring countries and abroad. Inferentially, if the locally made textiles and prints are preferred to the foreign imported products, this should result in increased demand for the local products to sustain the industry. However, the industry has experienced consistent decline as shown in Table 1. Currently a lot of workshops under trees and by road sides have been deserted and dilapidated (Field study 2014). This situation serves as evidence that reflects the decline state of the Adinkra textile cloth production. Again, Adinkra textile cloth printing is a dying art; there is a considerable decline in the use of Ghanaian cultural symbols (Kquofi et al., 2013) in textile prints.

Apart from the large manufacturing companies, there are other small-scale textiles and garment firms operating in the sector. These are mainly screen printers, tie and dye/batik cloth producers and dressmakers. Also, there are traditional or indigenous textiles such as Kente cloth (traditional woven fabric), Adinkra cloth (traditional hand printed cloth) and other types of undocumented woven fabrics available on the market. The focus of this paper is on the Adinkra cloth sub-sector which has also suffered from this decline.

Adinkra textile cloth needs to be reinvigorated in order to promote the symbols, preserve cultural material and sustain the business activities of the artisans for economic prosperity. It is believed that, this can be achieved through innovation and well-crafted dynamic competitive marketing strategies. However, crafting such a strategy requires current market situational analysis to determine the challenges facing the industry and examine the existing opportunities. These when determined, can shape the marketing strategy intended for this peculiar sub sector of the textiles industry in Ghana.

Several factors affect the small and medium scale enterprises worldwide and the Adinkra textile sub sector is among the SME's in Ghana. Some of the challenges and factors resulting in decline of SME's are lack of finance, low productivity, technology and managerial capabilities (Decker et al., 2006; Harvie, 2004; Ritchie \& Brindley, 2000). Currently, other factors that affect the SME's includes an intensified globalisation that offers cheap products to international markets, new and emerging technologies that renders old technologies obsolete, cost ineffective and inefficient in production processes (Zulkifli-Muhammad et al., 2009). These factors negatively impacts on SME's and especially small businesses located in Africa that are competing with other global giants.

Studies on SME's in Africa have focused on country specific issues. However, Abor and Quartey (2010) studied issues in the development of SME's using a comparative analysis between Ghana and South Africa. It was argued that, the development of SME's are hampered by several factors including finance, lack of managerial skills, equipment and technology, regulatory issues, and access to international markets (Anheier \& Seibel, 1987; Aryeetey et al., 1994; Gockel \& Akoena, 2002; Steel \& Webster, 1991).

On the small and medium scale enterprises in Ghana, Boakye (2008) suggested that there are numerous problems facing these companies. It was argued that internal capacity problems such as inadequate capital and lack of raw materials among others are the some of the problems of SMEs. Other external forces such as smuggling of manufactured textiles and garments from neighbouring countries like Togo, Benin and Nigeria and advance technologies in textiles and garments manufacturing of industrialised countries such as China and India.

A recent study that focused on one of the Ghanaian textile sub-sectors (cloth dyers) have been conducted by (Acquah \& Oduro, 2012). The study technically evaluated the challenges faced by the cloth dyers sub-sector empirically with emphasis on the production of dyes needed for use by the industry. Among the challenges are poor quality of dyes, lack of drying facilities with its attendant effect on operations during the raining season, difficulty in accessing fuel wood for boiling roots and barks to produce the dyes, and lack of financial support to expand businesses. The study focused on identifying the type of trees suitable for the dye production, example Kuntunkuni tree. The question that needs an answer is whether these reasons adduced for the sharp decline of the textiles industry and its sub-sector are the same reasons behind the drastic fall in the production and employment capacity of the traditional Adinkra textile cloth sub sector. 
Therefore, the present study is focused on the Adinkra hand printing textile cloth sub sector of the larger textile industry which is distinct from the cloth dyers in respect of designs, production and target group. Besides, the present study examines challenges and business opportunities within the sub sector for textile companies to better serve the needs of the market.

In summary, studies on the textile sector have focused on the SME's in general and the numerous challenges both from the broader African and country wide perspectives. In Ghana, it is the study of Acquah and Oduro (2012) that specifically considered the traditional cloth dyers textile sub sector. On the contrary, this study focuses on the traditional Adinkra hand printing textile sub sector.

This study therefore, sets out to determine the causes of declining state of the Adinkra sub sector and compare with studies on the textile sector in general to determine whether factors are same or otherwise, discuss the implications on this important sub-sector and present opportunities for sustaining the industry. Beyond this, industry and country wide implications of this decline are examined within the textile printing industry in Ghana with emphasis on the Adinkra textile cloth sub-sector. Lastly, it is an objective of this study to intellectually analyse the factors of decline, proffer solutions which can be turned into opportunities for businesses operating in the industry and other potential firms that may capitalise on the opportunities.

The study is organised into four main sections; introduction in section one, followed by research site and methods in section two and section three is dedicated to the discussion of the empirical results of the study and finally, the last section is used for conclusion and further research.

\section{Research Site and Methods}

\subsection{Adinkra Hand Printing Cloth}

A nation rich in history, Ghana has a unique culture with a continuous inheritance. One example is traditional symbols such as Adinkra. Adinkra is a visual image that combines aesthetics, history, wisdom, identity and the works of life of the people of Ghana (Quarcoo, 1972). Adinkra symbols serve as a tool for not only displaying aesthetic characters but also perceiving the world with its rich and deeper meanings. Adinkra symbols are usually imprinted on plain dark coloured fabric. These symbols are adopted as designs to produce symbolic textile cloth. Adinkra symbolic textile cloth is said to be the only African cloth printing tradition of pre-colonial origin and one of the prestigious royal craft (Clarke, 2011). In Table 2, samples of the symbols that are adopted as designs for the textile cloth is displayed with their names, meanings and roles. Figure 1 exhibits Adinkra textile printed cloth with a number of Adinkra symbols.

Table 2. Description of two Ghanaian Adinkra cultural symbols

\begin{tabular}{llll}
\hline SYMBOLS & NAMES OF SYMBOLS & LITERAL MEANINGS & ROLES \\
\hline & Akoma ntoaso & "Extension of the hearts" & Symbol of understanding and agreement \\
\hline
\end{tabular}

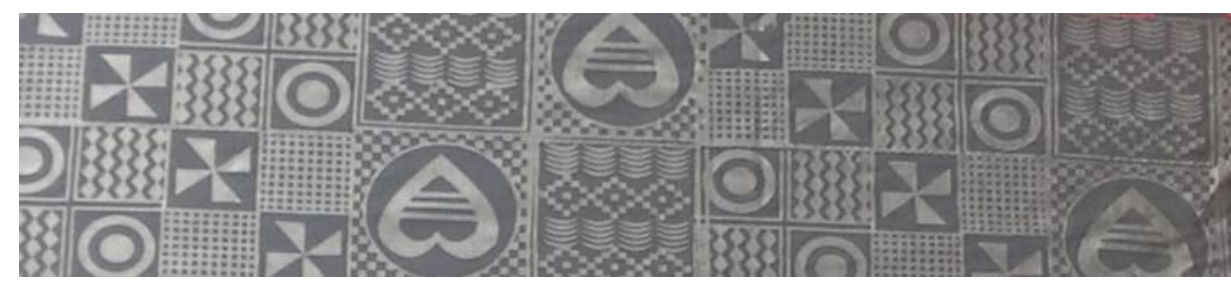

Figure 1. Adinkra textile cloth

\subsection{Geographical Location}

The production and marketing of Adinkra cloth is predominantly centred in the Ashanti region of Ghana. Specifically, the Kwabre East district of Ashanti region of Ghana is recognised for the printing and sale of local textiles known as Adinkra textile cloth. Many Ghanaians home and abroad used to patronise Adinkra textile cloth due to the meanings of the symbols hence, spreading their meanings. 
Ntonso, a town in the Kwabre East District of the Ashanti Region of Ghana is known as the centre of Adinkra textile cloth making. The town is Ghana's foremost Adinkra cloth design and manufacturing centre. As can be seen in Figure 2, the district is located in the central part of the Region. The Kwabre District shares common boundaries with Afigya Sekyere District, Kumasi Metropolitan Area, Ejisu-Juaben-Municipal, Offinso Municipal and Atwima District to the north, south, southeast, west and to the northwest respectively. The area lies within the geographical coordinates of $6050^{\prime} \mathrm{N}$ and $1031^{\prime} \mathrm{W}$ with a total land area of $24,700 \mathrm{ha}$, constituting about $1 \%$ of the total land area of the Ashanti Region. In Figure 2, Kwabre distirct is shown using a red rectagular shape. An arrow has also been pointed to show the location of Ghana in the Africa map.

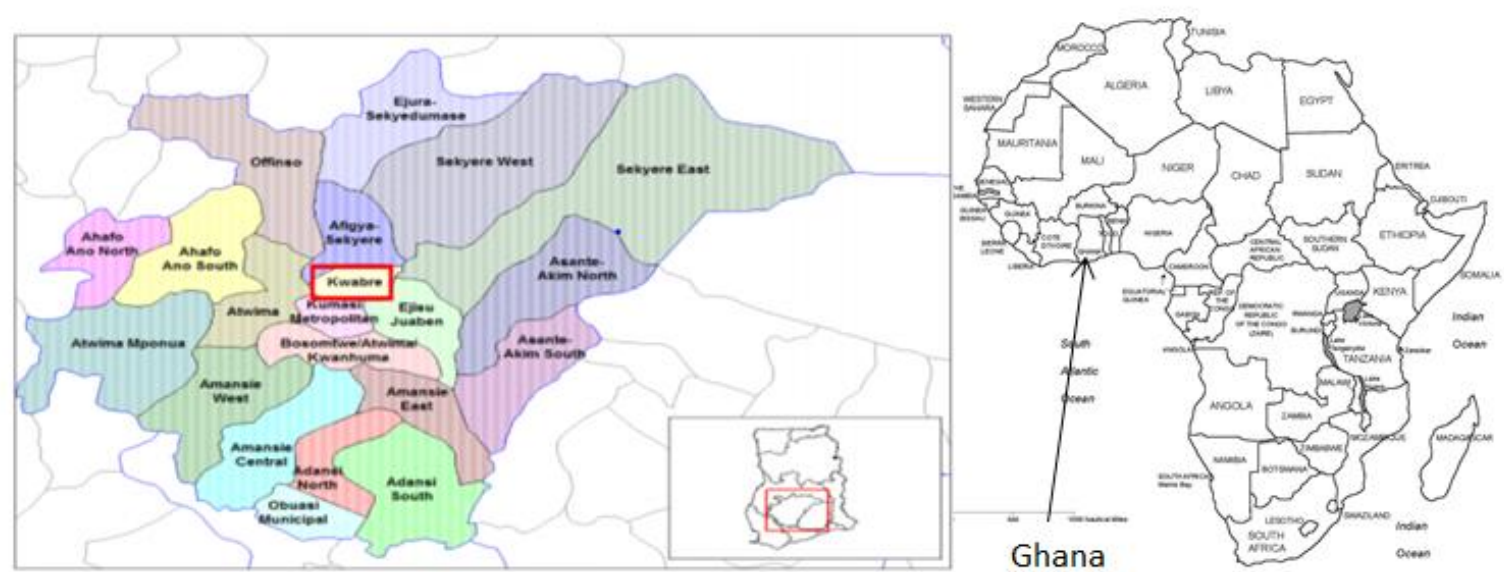

Figure 2. A map of Africa showing Ghana, and a map of Kwabre district in Ghana

Source: Bosome Freho District (2008) and Graphatlas.com (2015).

\subsection{Methods, Sample Size and Procedure}

This study adopted a mixed method approach. Mixed research methods generally refer to an approach of enquiry where a researcher combines aspects such as techniques, methods and data of both qualitative and quantitative in a single study (Greene et al., 1989; Johnson \& Onwuegbuzie, 2004). It is pluralistic and does not depend on a single source of enquiry to answer research questions. In this study, the research method adopted the mixing across stages where the primary data in the form of interviews was collected using a qualitative approach. However, in the analysis stage and data presentation, the qualitative data was quantized and descriptive statistics was used to present the findings in the form of percentages.

Specifically, semi-structured interviews were used as instruments of data collection which were conducted with managers, heads of departments and individuals drawn from key stakeholders within the textile industry of Ghana identified during the field work. The sampling approach used for the selection of interview participants was both stratified and purposive sampling. Firstly, the respondents were categorised based on their roles such as users, suppliers, producers and retailers. Afterwards, they were purposively selected to represent the different categories based on their level of experience and position in the respective organisation.

The total sample size is 35 participants (see Table 3 for sample size and respondents). The sample size of 35 is ideal for a qualitative research because qualitative researches normally place emphasis on richness of data (O'Leary, 2013) as opposed to quantitative research that depends on numbers to make generalizations. Besides, due to the number of 35 respondents which fulfils the normality assumption, the reseachers can infer the central limit theorem to make statistical generalisations from the data.

After the interviews with all the stakeholders was completed, the data collected was transcribed, coded and analysed by using standard software named NVivo to generate the different themes for the findings. The different themes emanated from the literature discussion and the interviews. The NVivo software generated tables with numerical information which was analysed using descriptive statistics such as percentages. This enhanced the analysis and delivered robust results that improved the presentation and discussion immensely. The results from the statistical analysis was presented, discussed and conclusions drawn for the study. 
Table 3. Stakeholder types and number included in the sample

\begin{tabular}{lc}
\hline Stakeholder group & Number in sample \\
\hline Textile printing companies & 4 \\
Clothing industry & 4 \\
User & 6 \\
Design institutions & 3 \\
Adinkra printing industries & 5 \\
Fabric suppliers & 2 \\
Retailers & 3 \\
Dye suppliers & 3 \\
Government support agencies & 3 \\
Trade associations & 2 \\
Total & 35 \\
\hline
\end{tabular}

\section{Results and Discussion}

The discussion section entails the presentation of the findings deduced from the analysis of the data collected from the field study. This discussion is grouped under the respective headings that were used for the interviews. In other words, a themed approach was used for the presentation of data and analysis.

\subsection{Nature of Dye, Colours and Cloth}

The interviews with the participants sought to identify the different factors that affect the businesses of the artisans. As a result, all the key stakeholders in the textile industry were asked of their views on the dye, its colour and the cloth in general. During the interview, 33 responses representing approximately $94 \%$ of the total respondents admitted that, as part of caring for the cloth, information given to users by retailers requires them not to wash. The reason adduced for such a requirement is the fact that the dye has been found as water soluble dye. Hence, bleeds out during wash. This is confirmed in an earlier research on the Adinkra textile cloths (Mato, 1986; Willoughby, 2005). Furthermore, from the field study it was identified that most dyes used in Adinkra textile cloth production is self-made by the artisans. These self-made dyes are generally poor in quality as compared to the factory dyes.

With regards to the colour of the dyes, it was realised that the main colour is black. Colour generally serves as an attraction for customers in purchasing products. An evidence is given by Bae and May-Plumlee (2005) who states that primarily, customers are attracted by the colour of a product. From the field study, colour was found to be relevant to the consumers because in Ghana, certain colours are associated with particular social activities. For example black colour is for funerals whereas white is generally used to represent victory. Hence, a desired change in attitude of users towards the cloth can be greatly enhanced through the use of different colours because consumers can have variety to choose from.

Moreover, responses received from the artisans who are mainly producers of the cloth suggest that, the cloth is of medium to heavy weight, usually cotton and cotton blends. As evidence, all the five Artisans who are mainly producers of the cloth responded in affirmative. The main reason given for the usage of this material is that, light weight fabrics absorb the dye and can result in unwanted leakages in the design of the cloth. This characteristic of the Adinkra textile cloth has negative impact on general and casual usage. It mostly prevents the user from constructing the cloth into garment styles more especially draped designs, if one desired to do so. This reason affects its appeal to a larger population to buy and make use for more widespread activities. Therefore, one of the barriers that prevent the usage of the cloths is the nature of the dyes, colour and weight of the cloth. Even though this particular characteristic is good for the production of the traditional cloth, any attempt at adapting the cloth to modern use must be associated with the necessary changes to suit the needs of the postmodern consumer.

\subsection{Access to Capital}

As discussed, the Adinkra cloth makers are small and medium enterprises (SME's). The SMEs are generally grouped into organised and unorganised enterprises. The organised companies are those with registered offices and can afford to pay the salaries of their employees whereas the unorganised category is mainly made of artisans that engage in the cloth making as an informal trade. These artisans work in open spaces, temporary wooden structures, or at home and employ little or in some case no salaried workers. The Adinkra artisans are placed into the informal category. From the field study, all the respondents representing $100 \%$ agreed that, access to capital is a great challenge. However, the level of access to capital for the business activities of the artisans 
was varied among respondents. The determination of the level of capital as a challenge was therefore ranked based on a standard from Low to High. The respondents were expected to rank the access to capital based on this standardised scores for better analysis. Using this standard rating, a response rate of approximately $6 \%$ agreed that, they have medium access to capital whereas the remaining $94 \%$ suggested that, access to capital is low and a great challenge. This clearly demonstrates the lack of access to capital to compete with other firms with huge capital base. In view of this, larger firms with huge capital base are able to secure funding for production from the financial institutions. Besides, the larger firms enjoy economies of scale in terms of production with low cost per unit of output and distribution. The lack of access to capital renders the small Adinkra textile groups handicapped in competing with the larger firms for the same clients. Participants in the interview responded that they usually rely on family members, life time savings, friends and donations to start their businesses, hence the inability to expand and improve the Adinkra textile cloth sub sector. This particular finding is supported by earlier studies (Fisseha, 1987; Mayers, 2006) who determined that, about $80 \%$ of financing for small and medium forest enterprises (SMFEs) comes from owners, families, friends and personal savings. Access to capital is also primarily due to artisans lacking the requisite collateral to attract mortgages from financial institutions. As discussed, they operate under trees and open spaces, hence cannot use those spaces as collateral. Several banks including commercial and rural banks are often unwilling to lend funds to SMEs due to perceived lack of business sustainability, credit unworthiness stemming from poor records keeping and low repayment of loans (Adu, 2009; Osei-Tutu et al., 2010). Practically, it was observed that, as a unit with proper operations through trade associations, this challenge can be surmounted because as a group, the credit worthiness can be improved drastically. On the contrary, the Adinkra textile cloth makers have actually been duped by some members through the formation of association. Therefore, this option, though has worked for other traditional forms of textile cloth makers (Osei-Tutu et al., 2010), does not seem appropriate for the Adinkra textile cloth producers due to the bad experience. Among the solutions to this problem can be in the form of organising the temporary structures into permanent structures with good records keeping for the business to enhance proper assessment and creditworthiness.

\subsection{Supply Chain Issues}

Supply chain is cardinal to the distribution of products to reach the final consumer and a way of receiving feedback from clients and users of a product. In this same vein, Acquah and Oduro (2012) highlight supply chain as a platform for collaboration in determining many productive activities among all members of small and medium scale enterprises. The levels of existing supply chain or communication strategies within and across industries determine their products and services, improvement in production, economic prosperity and development of new business platforms (Tsai, 2001). From the field data collection, it was also determined that, there is lack of collaboration among the key players in the industry, herein referred to as the stakeholders. As detailed in Table 1, the stakeholders noted are textile printing companies, clothing industry, users, design institutions, Adinkra printing industries, fabric suppliers, retailers, dye suppliers, government support agencies and trade associations. These stakeholders are supposed to collaborate and deliver an end user driven product that satisfies the need of clients and consumers. In practice however, they operate in a disjointed manner and the artisans produce textile cloths based on their intuition without any rigorous marketing research to satisfy the needs of clients. Besides, the other stakeholders that can serve as sources of valuable information are also not contacted in the production of the textile cloths. The effect of this lack of collaboration is the production of products that do not meet the needs of customers. Therefore, this hampers the marketing activities of the artisans leading to lack of patronage for the final products. This lack of an effective supply chain is evident by the field data that depicts that, 21 respondents representing $60 \%$ suggested a low level of collaboration among the stakeholders. Again, 11 respondents representing approximately $31 \%$ suggested a medium collaboration whereas the remaining paltry number of 3 respondents denoting $9 \%$ confirmed a high level of collaboration. Clearly, this demonstrates a lack of collaboration among artisans and other stakeholders.

In view of the lack of collaboration among the key stakeholders, a high rate of $88.5 \%$ of users is unsatisfied with the end product from the artisans. This represents 31 respondents with the remaining 4 respondents signifying that, the level of satisfaction is at medium level. In this instance, it must be stated that, all the stakeholders were considered to be part of the users because they also use some of the products occasionally. As a result, an effective supply chain that can enhance collaboration among stakeholders must be developed to ensure that, the needs of clients are factored into the production of the textile cloths to enhance end user satisfaction. This has the potential to induce patronage from the clients and other users of the products. Due to non-existence of an effective supply chain for the distribution of the products, the producers cannot determine the final price of Adinkra textiles cloth. As a result, there was price discrimination which is unfavourable because the users paid 
exorbitant prices as compared to other manufactured textile cloths on the market and this became evident from the field study.

\subsection{Outmoded Forms of Production Technology}

The artisans who responded during the interview affirmed that, the technology is quite laborious and time consuming. Even though they expressed sentiments about the technology, much has not been done to improve upon this technology which has been in use before 1927. One peculiar problem that the artisans emphasised on is the difficulty of acquiring the raw materials for production. The most challenging part is the dyes needed for printing the textile cloths. The locally manufactured dyes are very difficult to produce. They are normally obtained from processing barks and roots using an outmoded form of technology. After the laborious work to produce the dyes, they are also of low quality. This is primarily due to the fading nature of the dyes after using the textile cloth. Several attempts have been made to improve upon the process of producing the dyes. For example a grinding machine was introduced for grinding bark of tree. However the introduction of this machine worsened matters as the end product did not meet the expectations of the artisans. At present, the most reliable means of acquiring the quality dyes is from the established manufacturing firms in the textile industry. However, these factory dyes imported by the established firms were meant to be used for their production and not for retail purposes. This makes it difficult for the artisans to find the appropriate dyes for the production of the textile cloths. From the field work, all the respondents agreed that, the scientific dyes (factory dyes) have high degree of reliability as compared to the locally made dyes by the artisans. This was evidenced by the responses from 14 (40\%) and $21(60 \%)$ respondents who suggested that, the scientific dyes are reliable and highly reliable respectively. This results confirmed the findings of Acquah and Oduro (2012), who discussed that there is the need for the development of new dyes to replace the old fugitive dyes. In view of this, it is important that, industry and stakeholders take the necessary steps to develop new dyes in order to sustain the business.

\subsection{Implications}

The decline in the industry is as a result of low demand for products as reported earlier in Table 1. This has consequences for an industry that attracts a considerable number of tourists all year round. According to Holden et al. (2011), the total number of tourists arriving in Ghana in 2009 were 74,293 and according to the World Bank (2015), the total number of tourists that visited Ghana in 2010 amounted to 931,000 . These tourists patronise the Adinkra traditional textile cloths as souvenirs especially products such as scarves and other portable items made of Adinkra cloth. It can be inferred that, this sector contributes greatly to the economy of Ghana. Therefore, the collapse of the Adinkra textile sub sector which also attracts a considerable number of tourists means the loss of important revenue to the state from tourism as well as taxes from the numerous retailers, producers, dye suppliers, fabric manufacturers, designers and other stakeholders who are indirectly connected to the industry. Besides, the artisans who gain their livelihood from this trade are also likely to lose their jobs in the process. Moreover, a tradition that has lasted for over a century is likely to extinct, hence altering the great history of a society.

The non-existence of supply chain has also resulted in price discriminations of the products from the producers to the final consumers where retailers are able to price products without regard to consumers ability to afford. This also affects the demand for the products as the prices are sometimes highly inflated. Besides, the issue of the supply chain also has negative effects on the distribution and good feedback from the users of the cloths for improvements.

As these problems and the challenges are seen as surmountable, these solutions are proffered as part of our analysis of the issues presented. Firstly, there should be an effective supply chain network that can directly enhance the collaboration between the different stakeholders identified in this study. If the supply chain network is developed, the wider implications will be a control of the end user price of the textile cloth to ensure a competitive pricing on the market in comparison with other textile products on the market. As Ghana is a least developed country, price differentials are likely to be pivotal in a diffusion strategy to ensure adoption of the textile product.

Moreover, access to capital is a central theme to all small scale industries. In this regard, the identification of the trade associations as one of the stakeholders of this study can serve as a breakthrough to attract the needed capital in the form of group loans from micro finance companies. The formation of these associations would result in the pooling together of resources that can serve as collateral for acquisition of a mortgage. This must also come with stringent control to curb the menace of duping artisans. 


\subsection{Business Opportunities}

Due to the numerous challenges exposed as plaguing the Adinkra textile cloth sub sector, an analysis also revealed several untapped business opportunities that can be harnessed to develop this sub sector to improve upon the general textiles industry. Firstly, due to the absence of an effective supply chain, distribution activities of the industry are ineffective. In this sense, a very effective supply chain can be developed to enhance product distribution through the chain beginning from the artisans who are the producers to the final consumers who are the users of the products. This will ultimately create a system of closed loop where the producers can receive feedback on their products in order to factor them into customer needs when producing the textile cloths. There will also be an improvement in customer satisfaction, leading to the adoption of the textile cloths.

Moreover, if price can be used as a competitive tool in order to break into the established markets such as the broader local and international textiles industry, there is the need for the producers to be able to take control of their supply chain. The development of the supply chain can also enhance the competitive advantage of the products in order to determine new ways to make the textile products meet the needs of the marketplace and serve the target clients.

Lastly, it has been discussed that, the technology for the production of the textile cloths is outmoded. In view of this, it is proposed that, firms with the technical know-how should develop modern technologies for the production of the textile cloths. This has the potential to open up a new line of business for expansion of the Adinkra textile market. This will drastically reduce the total work and time involved in the production of the Adinkra textile cloth.

In summary, this study has identified the numerous challenges bedevilling the Adinkra textile sub-sector of the Ghanaian textile industry. Based on these challenges, an intellectual analysis was developed to proffer solutions to these problems after which the business opportunities existing in the industry has been presented. It is argued that, with all the solutions espoused in this study, the quality, production and promotion of the Adinkra textile cloth can be improved considerably. This has the potential to improve the demand for the textile cloth leading to economic prosperity for the artisans and contribution to the economy of Ghana.

\section{Conclusion}

In this study, the theme was to determine the factors that account for the decline of the Adinkra textile sub sector, which is part of the main textile industry in Ghana. Stemming from the discussions of the findings, it is evident that, the factors that inhibit the ability of producers of the Adinkra textile cloth to develop the industry and reach the final consumer with the product are varied as compared to those found in earlier studies. Some of the factors corroborate the findings of earlier studies but there are new factors that were identified to be specific to the Adinkra textile cloth sub sector including the nature of dyes and colours of dyes, end user satisfaction and supply chain issues. These were in addition to the general factors such as poor access to capital and outmoded technology.

The study has examined the challenges and presented the existing opportunities that have the potential of transforming the Adinkra textile sub sector. Solutions to the numerous problems have been proffered to enable policy makers and stakeholders take action to sustain the sub sector due to its heritage importance and contribution to the economy. The study has unravelled avenues for business opportunities for local and international firms to invest in the Adinkra textile sub market for expansion and profitability.

\section{References}

Abor, J., \& Quartey, P. (2010). Issues in SME development in Ghana and South Africa. International Research Journal of Finance and Economics, 39(6), 215-228.

Acquah, B. S., \& Oduro, K. A. (2012). Traditional cloth dyeing enterprise at Ntonso: Challenges and opportunities. West African Journal of Applied Ecology, 20(1), 25-35.

Adu, G. (2009). Business support platforms for SMFEs in Ghana. Paper presented at the Tropenbos-IIED Workshop on Small and Medium Forest Enterprises in Ghana on March 26-27.

Anheier, H. K., \& Seibel, H. D. (1987). Small-scale industries and economic development in Ghana: Business behavior and strategies in informal sector economies. Saarbruckh, Germany: Verlag Breitenbach.

Aryeetey, E., Baah-Nuakoh, T., Duggleby, H. H., \& Steel, W. F. (1994). Supply and demand for finance of small enterprises in Ghana. World Bank Discussion Paper No 251. Washington, D. C.

Bae, J., \& May-Plumlee, T. (2005). Customer focused textile and apparel manufacturing systems: Toward an effective e-commerce model. Journal of Textile and Apparel, Technology and Management, 4(4), 1-19. 
Boakye, Y. A. (2008). Challenges facing the small-scale textiles and garments industry in Ghana. (Unpublished master's thesis), Kwame Nkrumah University of Science and Technology, Ghana.

Bosome Freho District. (2008). Bosome Freho District. Retrieved from http://www.wikiwand.com/en/Bosome_Freho_District

Clarke, D. (2011). Adire African Textiles: Asante Adinkra Cloth. Retrieved from http://www.adireafricantextiles.com/adinkraintroduction.htm

Decker, M., Schiefer, G., \& Bulander, R. (2006). Specific challenges for small and medium-sized enterprises (SME) in M-business. Paper presented at the Proceedings of the International Conference on E-Business (ICE-B 2006), Setúbal, Portugal: INSTICC.

Fisseha, Y. (1987). Basic features of rural small-scale forest-based processing enterprises in developing countries. Paper presented at the Small-Scale Forest-Based Processing Enterprises. Food and Agricultural Organization (FAO) of the United Nations, forestry Paper 79, Rome, Italy.

Gockel, A. F., \& Akoena, S. K. (2002). Financial intermediation for the poor: Credit demand by micro small and medium scale enterprises in Ghana: A further assignment for financial sector policy? IFLIP Research Paper 02-6. Geneva: The International Labour Organisation.

Graphatlas.com. (2015). Africa political map in black and white. Retrieved from http://www.graphatlas.com/political_map_of_africa_black_and_white.jpg

Greene, J. C., Caracelli, V. J., \& Graham, W. F. (1989). Toward a conceptual framework for mixed-method evaluation designs. Educational Evaluation and Policy Analysis, 11(3), 255-274. http://dx.doi.org/10.3102/01623737011003255

Harvie, C. (2004). East Asian SME capacity building, competitiveness and market opportunities in a global economy. Faculty of Commerce-Economics Working Papers, 100.

Holden, A., Sonne, J., \& Novelli, M. (2011). Tourism and poverty reduction: An interpretation by the poor of $\begin{array}{lllll}\text { Elmina, Ghana. Tourism Planning \& Development, } & 8(3), \quad 317-334 .\end{array}$ http://dx.doi.org/10.1080/21568316.2011.591160

Johnson, R. B., \& Onwuegbuzie, A. J. (2004). Mixed methods research: A research paradigm whose time has come. Educational Researcher, 33(7), 14-26. http://dx.doi.org/10.3102/0013189X033007014

Kquofi, S., Amate, P., \& Tabi-Agyei, E. (2013). Symbolic representation and socio-cultural significance of selected Akan proverbs in Ghana. International Institute For Science, Technology \& Education, 3(1), 86-98.

Mato, D. (1986). Clothed in symbol-The art of adinkra among the Akan of Ghana. Indiana: Bloomington.

Mayers, J. (2006). Small-and medium-sized forestry enterprises. International Tropical Timber Organization (ITTO) Tropical Forest Update, 16(2), 10-11.

O'Leary, Z. (2013). The essential guide to doing your research project. Los Angeles: Sage.

Osei-Tutu, P., Nketiah, K., Kyere, B., Owusu-Ansah, M., \& Faniyan, J. (2010). Hidden forestry revealed: Characteristics, constraints and opportunities for small and medium forest enterprises in Ghana. London: Russel Press.

Quarcoo, A. K. (1972). The language of the adinkra patterns. Legon: Institute of African Studies.

Quartey, P. (2006). The textiles and clothing industry in Ghana. In H. Jauch, \& R. Traub-Merz (Eds.), The future of the textile and clothing industry in Sub-Saharan Africa (pp. 135-146). Germany: Bonn: Friedrich-Ebert-Stiftung.

Quartey, P., \& Abor, J. (2011). Do Ghanaians prefer imported extiles to locally manufactured ones? Modern Economy, 2, 54-61. http://dx.doi.org/10.4236/me.2011.21009

Ritchie, B., \& Brindley, C. (2000). Disintermediation, disintegration and risk in the SME global supply chain. Management Decision, 38(8), 575-583. http://dx.doi.org/10.1108/00251740010378309

Steel, W. F., \& Webster, L. M. (1991) Small enterprises in Ghana: Responses to adjustment industry. Series Paper. Washington, D. C.: The World Bank Industry and Energy Department.

Tsai, W. (2001). Knowledge transfer in intraorganizational networks: Effects of network position and absorptive capacity on business unit innovation and performance. Academy of Management Journal, 44(5), 996-1004. http://dx.doi.org/10.2307/3069443 
Willoughby, J. (2005). Adinkra Printed Ceremonial Clothes of Ghana. Hampton: An Ends of the Earth Surviving Traditions Production.

World Bank. (2015). Internationa tourism, number of arrival. Retrieved from http://data.worldbank.org/indicator/ST.INT.ARVL

Zulkifli-Muhammad, M., Char, A. K., Bin Yasoa, M. R., \& Hassan, Z. (2009). Small and medium enterprises (SMEs) competing in the global business environment: A case of Malaysia. International Business Research, 3(1), 66. http://dx.doi.org/10.5539/ibr.v3n1p66

\section{Copyrights}

Copyright for this article is retained by the author(s), with first publication rights granted to the journal.

This is an open-access article distributed under the terms and conditions of the Creative Commons Attribution license (http://creativecommons.org/licenses/by/3.0/). 